\section{By Sharon Smaldino}

0 nce again we enter the final issue of a year-long exploration of linking research and practice with a focus on learning. This year's final issue explores a number of issues of importance to professionals in the educational communications and technology fields.

Our featured articles in this issue provide readeers with a wealth of information on a variety of topics. The nature of the field is such that often what appear to be disconnected actually have many links within. As you read through these pieces you will find there are some very interesting aspects of each article that fit nicely into your professional responsibilities.
This issue includes the call for proposals for the 2009 AECT Inernational Convention. The convention theme is Integrative Approaches: Meeting Challenges. Convention planners have already identified some unique approaches to the event's structure. Keep an eye on upcoming TechTrends issues for more information. Please make a note of the proposal deadline of February 14, 2009.

Once again I wish to thank all our column contributors for their hard work in bringing us new information and ideas. The information they provide helps all of us in our quest for new knowledge. I would be remiss if I did not also thank Jean Callary for her hard work and energy in all the work she does to bring together a quality publication.

\section{Corrections:}

The November/December issue failed to include the biographical statement for Christopher Adamsick, author of the Copyright and You column. With apologies to Christopher, that information is included here:

Christopher T. Adamsick completed his doctorate in instructional technology in August 2008 from Northern Illinois University. His doctoral dissertation, entitled The Signifcance of the Instructional Medium: A Phenomenological Anal$y$ sis and Interpolation, directly addresses the issues and concerns that underlie the two-decade old, great media debate of instructional technology. Christopher was a community organizer for the presidential campaign of now-President Barack Obama. He is an advocate for mental health services consumers of DeKalb County. Christopher plans a career in academic librarianship.

Also, in the November/December issue, an incorrect reference was made to the first year of the Graduate Student Assembly. The first year of the GSA was 2006.

\title{
TechTrends
}

A Peer-Reviewed Publication

The official publication of the Association for Educational Communications and Technology (AECT) for leaders in education and training. ISSN 8756-3894

1800 North Stonelake Drive Suite 2

Bloomington, Indiana 47404-1517

Phone 812-335-7675 • Fax 812-335-7678

Toll-free 877-677-AECT

email aect@aect.org

\begin{tabular}{lr}
\multicolumn{2}{c}{ AECT Board of Directors } \\
President & Mary Herring \\
President-elect & Michael Spector \\
Secretary-Treasurer & Mary Beth Jordan \\
Past President & Pat Miller
\end{tabular}

Board Members

Robert Branch, Ted Frick, Mary Herring, Jenny Johnson, Susan Jones, Mary Beth Jordan, Addie Kinsinger, Donal Little, Barbara Lockee, Trey Martindale, Kay Persichitte, Scott Schaffer, William Sugar, David Wiley

TechTrends Publisher

Editor-in-Chief

Editor

Design Director

Departments Editor

Consulting Editors

Don Descy, Steve Hackbarth, Mary Herring, Terry Holcomb, Gary Powell, Michael Simonson, David Tiedemann, Robert Wiseman, Jane Zahner

ID Portfolio Editors

Elizabeth Boling, Senior Editor. Abbie Brown, Adam Fischler, Michael M. Grant, Linda Lohr, Lauren Cifuentes, Wei-Chen Hung, Susan Pedersen, Francine Shuchat Shaw

\begin{tabular}{lr}
\multicolumn{2}{c}{ Column Editors } \\
$\begin{array}{lr}\text { All Aboard the Internet } \\
\text { Connelly's Cutaway }\end{array}$ Don Descy \\
Copyright and You & John and Marilyn Connelly \\
ect Cornerstone & Preston Parker \\
ICT Portfolio & Robert Harrell \\
Learning by Design & Ross A. Perkins \\
Professional Ethics & Joe Landsberger \\
The History Corner & Andrew Yeaman \\
The Mentoring of Media & Rebecca P. Butler \\
& Linda Bartrom
\end{tabular}

Consulting Reviewers

Eun-Ok Baek, Brian Beatty, Barbara A. Bichelmeyer, Doris U. Bolliger, Carol A. Brown, Thomas A. Brush, Betty Collis, Michael Corry, Vanessa Dennen, Peg Ertmer, Dolores Fidishun, Rob Foshay, Theodore Frick, David A. Goodrum, Charles R. Graham, Noriko Hara, Kathleen W. Ingram, John B. Keller, Tiffany A. Koszalka, Byung-Ro Lim, Donal Little, Trey Martindale, Al Mizell, Trena M. Paulus, James A. Pershing, John R. Savery, Krista D. Simons, Rosemary Talab, Walt Wager, Lisa C. Yamagata-Lynch

Editorial material published herein is the property of AECT unless otherwise noted. Opinions expressed in TechTrends do not necessarily reflect the official position of AECT. All artwork (c) Ned Shaw except where noted.

Permissions: Copyrighted material from TechTrends may be reproduced for noncommercial purposes provided full credit acknowledgement and a copyright notice appear on the reproduction. Other requests for reprinting should be addressed to AECT Permissions. 